\title{
Prevalence and determinants of malnutrition among under-five children in Lusaka urban, Zambia
}

\author{
Emmanuel Mwila musenge*, Sophia Tembo, Mutinta Hankwebe, Ndonia Kahinga, Ovy Mushibwe, \\ Ivy Mulenga, Suzane Tembo
}

Department of Basic and Clinical Nursing Sciences, School of Nursing, University of Zambia, P.O. Box 50110, Ridgeway Campus, Lusaka, Zambia.

\begin{abstract}
Background: Malnutrition is a severe and persisting cause of morbidity and mortality among under-five children in Zambia. We assessed malnutrition and its determinants among under-five children in Lusaka urban, Zambia.

Methods: This cross-sectional study was conducted at Chawama, Kabwata, Chilenje and Mtendere urban clinics in Lusaka. A simple random sample of 384 under-five children were selected between February and March 2015. A structured interview schedule was used to collect data on demographic characteristics, determinants of malnutrition and anthropometric measurements. Multivariate binary logistic regression analysis was carried out using IBM ${ }^{\circledast}$ SPSS $^{\circledast}$ Statistics for Windows Version 20.0 to identify determinants of malnutrition while adjusting for confounders.

Results: Of the 384 under-five children, $51.8 \%$ of them were male and the mean (SD) age was $13.83 \pm 10.17$ months. The $\mathrm{zH} / \mathrm{A} ; \mathrm{zW} / \mathrm{H}$; and $\mathrm{zW} / \mathrm{A}$ were $68.5 \%$ and $31.5 \% ; 95.6 \%$ and $4.4 \%$; and $86.2 \%$ and $13.8 \%$ for normal and stunted; normal and wasted; and normal and underweight respectively. Majority (77.1\%) of the children had MUAC $>12.5 \mathrm{~cm}, 16.9 \%$ had $11.5-12.5 \mathrm{~cm}$ and $6.0 \% \mathrm{had}<11.5 \mathrm{~cm}$. Mother's good nutritional practices (OR 0.50 , 95\% Cl: $0.27-0.95)$ and $\mathrm{MUAC}>12.5 \mathrm{~cm}$ (OR 0.10, 95\% Cl: $0.01-0.94$; OR 0.01, $0.00-0.10$; and OR 0.4, 0.01 $0.19)$ were statistically significantly associated with stunting, wasting and underweight respectively.

Conclusion: We established varied levels of stunting, wasting and underweight and mother's nutritional practices and MUAC predicted these levels. More information, education and communication messages to the mothers and caretakers with regard to nutritional practices are needed so that under-nutrition can be improved, to ensure healthy living for mothers, care takers and under-five children.
\end{abstract}

Keywords: Malnutrition; Under-five children; Anthropometry; Nutritional assessment, Zambia.

\section{Introduction}

Malnutrition is a serious medical condition resulting from relative or absolute deficiency or excess of one or more essential nutrients in the human body (Mengistu et al., 2013). It is a direct cause of mortality, and a major disabler preventing children who survive to reach their full developmental potential (Central Statistical Office [CSO] et al., 2014). Of the 667 million under-five children globally, $23.8 \%, 7.5 \%$ and $6.1 \%$ were estimated to be stunted, wasted and overweight respectively in 2014 (United Nations Children's Fund-Word Health Organization-Word Bank [UNICEF-WHO-WB], 2015). The prevalence of stunting is decreasing while overweight prevalence is increasing worldwide (UNICEF-WHO-WB, 2015). In developing countries, about $32.0 \%$ under-five children are stunted and $10.0 \%$ are wasted (CSO et al., 2014). In 2014, 57.0\% and 37.0\%, 68.0\% and $28.0 \%$, and $48.0 \%$ and $25.0 \%$ of all stunted, wasted and overweight under-five children lived in Asia and Africa respectively (UNICEF-WHO-WB, 2015). Malnutrition is responsible for at least $35.0 \%$ of under-five children deaths worldwide (Roberfroid et al., 2007; WHO, 2014) and nearly half of under-five deaths are attributable to undernutrition (UNICEF et al., 2014).

The underlying causes of malnutrition are poverty, food insecurity, poor education, gender inequity, Human Immunodeficiency Virus and Acquired Immune Deficiency Syndrome (HIV and AIDS), inadequate parental care, introducing mixed feeding in the first six months, feeding type, early weaning, delayed introduction of complementary foods, a low-protein diet and severe or frequent infections, being a twin and higher levels of gestational malnutrition (CSO et al., 2014).

\footnotetext{
*Corrresponding E-mail: emmanuel.musenge@unza.zm or emmasenge@yahoo.com
} 
The most used anthropometric nutritional status indicators are Height-for-age $(\mathrm{H} / \mathrm{A})$, weight-for-height $(\mathrm{W} / \mathrm{H})$, Weight-for-age $(\mathrm{W} / \mathrm{A})$, and mid-upper arm circumference (MUAC) in all under-five children and Body Mass Index (BMI) in children over two years old (WHO, 2012). MUAC has been proposed as an alternative index for wasting and particularly in situation where data on height, weight, and age are difficult to collect (WHO, 2012).

Studies have been conducted on under-five malnutrition mostly in developing countries. In Brazil, underweight and overweight prevalence was $12.2 \%$ and $6.6 \%$ respectively in 2010 (Ramalho et al., 2013). Underweight was associated with wealth index, biological parents, maternal height and presence of open sewage, while overweight was associated with child's age, mother's duration of residence, mother's BMI (Ramalho et al., 2013).

In India, $49.4 \%, 28.5 \%$ and $51.1 \%$ of the children were stunted, wasted, and undernourished correspondingly (Pandve \& Singru, 2012). In Pakistan, 17.0\%, 3.0\% and 80\% of under-five children were stunted and severely stunted, underweight, and normal respectively and macronutrient and micronutrient deficiencies were prevalent in the studied population (Hassam et al., 2010).

In Ethiopia, under-five stunting was $42.3 \%$, with $20.4 \%$ severely stunted (Zeleke \& Rahman, 2013). Parents' education, household wealth index, age of household head, child's age, months of breast-feeding, place of delivery, media exposure, mother's BMI and residential differentials determined both severe and moderate forms stunting. In Nigeria, $12.5 \%, 14.8 \%$, and $8.5 \%$ under-five children were stunted, wasted and underweight respectively and $2.6 \%, 3.4 \%$ and $94.1 \%$ had MUAC < $12.5 \mathrm{~cm}, 12.5-13.5 \mathrm{~cm}$, and $>13.5 \mathrm{~cm}$ respectively (Akorede \& Abiola, 2013). Household income, mother's education and hygiene correlated with malnutrition. In Ghana, $28.0 \%, 8.0 \%$ and $13.0 \%$ under-five children were moderately 'stunted', moderately 'wasted' and moderately 'underweight' respectively and older age determined stunting and underweight (Aheto et al., 2015).

In Kenya, 47.0\%, $2.6 \%$ and $11.8 \%$ under-five children were stunted, wasted and underweight respectively (Olack et al., 2011). Child's age, sex, informal settlement and poverty were associated with stunting and wasting. In Botswana, stunting, wasting and underweight in children underthree years of age was $38.7 \%, 5.5 \%$ and $15.6 \%$ respectively and sex, employment status of parents, single parent, family income, mother's education and breastfeeding were associated with malnutrition (Mahgoub et al., 2006).

Zambia is the highest undernourished country in Africa and second in the world after Haiti (Food and Agriculture Organization of the United Nations [FAO] et al., 2014). One in two under-five children are stunted or chronically malnourished in Zambia (Chanda, 2014). Malnutrition is a severe and persisting cause of morbidity and mortality among under-five children in Zambia and it currently stands at 40\% (FAO et al., 2014). In 2013, 40.0\%, 6.0\% and 15.0\% under-five children in Zambia were stunted, wasted and underweight respectively (CSO et al., 2014). In comparison to other provinces, Lusaka has the least prevalence of stunting at $10.0 \%$ due to an increase in the mother's educational level. Approximately $50 \%$ of all the deaths and $30 \%$ of morbidity in under-five children in Zambia are due to malnutrition (FAO et al., 2014). Under-five malnutrition affects physical and mental development resulting in lower levels of educational attainment (Chanda, 2014).

Child growth monitoring is one of the tools UNICEF has recommended to assess the growth of the under-five children. Other promotive health measures in the package include; immunizations, vitamin A supplementation and deworming of children. Similarly, a maternal package of effective nutritional interventions to reduce the levels of chronic malnutrition has been globally agreed upon by experts in the field. Given the close link between under-nutrition and infections, the implementation at scale of interventions aimed at preventing and treating infections such as diarrhoea and malaria control will further contribute to malnutrition reduction (UNICEF, 2012; Ministry of Health [MOH], 2014). However, the prevention and control of malnutrition has proved difficulty despite the interventions being applied and emphasized during child growth monitoring at under-five children's clinic and the prevalence rate of malnutrition still remains high in Zambia. We assessed the nutritional outcomes, and identified the factors that may 
influence nutritional status of under-five children in the Lusaka urban of Zambia. The findings will assist in monitoring and evaluation of existing maternal and child health services, nutritional services and the development of new programs in combating under-five malnutrition.

\section{Materials and Methods}

\section{Study design}

This cross-sectional study was carried out at Chawama, Chilenje, Kabwata and Mtendere urban clinics in Lusaka district of Zambia. Mtendere and Chawama are densely populated areas with the majority of people belonging to the low socio-economic class. Chilenje and Kabwata are sparsely populated areas with the majority belonging to the middle and upper socio-economic classes respectively (CSO et al., 2014). The urban clinics provide maternal and child health services among others. The parents or caretakers bring their under-five children to the clinics at appointed times and whenever necessary for free support of child's health and development from birth until school age.

The participants included all under-five children from four zonal Lusaka urban clinics brought for growth monitoring activities whose parents or caretakers gave both informed and written consent. Nevertheless, all the children who were recruited in the previous weeks or months were excluded from the study. A simple random sampling method was used and participants were selected successively from February to March, 2015 leaving no room for sampling bias. The participants were selected based on the daily sampling frame. The sample size was calculated basing on the prevalence formula for calculating sample size of an unlimited population. The calculated sample size consisted of 384 under-five children.

\section{Data collection}

A structured interview schedule was used to collect data on demographic characteristics, determinants of malnutrition and anthropometric measurements. The same tool was used on all the participants to ensure reliability and validity. The data on demographic characteristics and determinants of malnutrition were obtained by interview and review of medical records.

\section{Anthropometric measurements}

The weight (WT), height/length (HT/LG) and MUAC of the participants were measured using a Salter weighing scale (Wuxi weigher factory company [Co], limited [Ltd], Zhejiiang, China), stadiometer (Mechanical stadiometer, Supplier Medexcel, New Delhli, India) and a tricoloured strip (Shanghai Jinda plastic Co Ltd, Shanghai, China) respectively. The BMI was calculated from the HT and WT based on the formula developed by the Belgian astronomer, statistician, mathematician and sociologist, Lambert Adolphe Jacques quételet in 1835 (Garabed, 2007). A scientific calculator FX-82ES (CASIO computer Co. Ltd, Tokyo, Japan) was used to obtain the actual BMI figure by dividing WT in kilograms $(\mathrm{kg})$ with $\mathrm{HT}$ in squared meters $\left(\mathrm{m}^{2}\right)$ which was also verified by the BMI Chart (WHO, 2006). These measurements were later on entered onto the interview schedule.

Malnutrition can be acute or wasting $(W / H)$, chronic or stunted $(H / A)$ and underweight (W/A) (WHO, 2012). Children whose H/A, W/H and W/A standard deviation (SD) of Z-scores fall below -2 the median (mean) values of the international reference are considered stunted, underweight and wasted, respectively (WHO, 2012; CSO et al., 2014) or by a MUAC bellow $11.5 \mathrm{~cm}$ (WHO, 2012; CSO et al., 2014). In addition, severe acute malnutrition is defined by MUAC $<11.5 \mathrm{~cm}$ for under-five children, W/H SD score $<-3$ and / or presence of oedema in both feet (WHO, 2012). Moderate acute malnutrition is MUAC of greater than $11.5 \mathrm{~cm}$ but less than $12.5 \mathrm{~cm}$ and W/H SD score of less than - 2 (WHO, 2012). Severe chronic malnutrition is H/A SD Score $<-3$ and MUAC $<11.5 \mathrm{~cm}$ (WHO, 2012). Moderate chronic malnutrition H/A SD Score $<-2$ and MUAC of $>11.5 \mathrm{~cm}$ but $<12.5 \mathrm{~cm}$ (WHO, 2012). Children whose SD of Z-score is above 2 and MUAC above $12.5 \mathrm{~cm}$ are considered overweight in consistency with clinical practice (WHO, 2012; CSO et al., 2014). Child's BMI is categorized using variable thresholds (specific Z-score or centile) for the child growth reference 
used that take into account the child's age and sex. The calculated child's BMI is then checked to see whether it is above or below the defined thresholds (Dinsdale et al., 2011).

\section{Data analyses}

Statistical analyses were carried out using IBM ${ }^{\circledast}$ SPSS $^{\circledast}$ Statistics for Windows Version 20.0 (IBM Corp. Armonk, NY, USA). The frequencies and descriptive statistics of the variables were calculated. The Chi-squared and Fisher's exact tests were used to select possible determinants of malnutrition. The Odds Ratio and 95\% confidence interval were calculated using binary logistic regression to identify determinants of malnutrition while adjusting for confounders. A $p$-value of $<0.05$ was considered significant.

\section{Results}

\section{Demographic and socio-economic characteristics of the participants}

The total number of under-five children included in this study was 384 . Of these, $199(51.8 \%)$ were male and 185 (48.2\%) were female. Slightly over half (201; 52.3\%) of the children were aged $0-11$ months, 134 (34.9\%) and 49 (12.8\%) were aged $12-24$ and $25-59$ months, respectively. Most (273; $71.1 \%$ ) of the children had birth weight (BWT) between $2.5-3.5 \mathrm{~kg}, 63(16.1 \%) \mathrm{had}<2.5 \mathrm{~kg}$ and 49 $(12.8 \%)$ had BWT of $>3.5 \mathrm{~kg}$. Majority (337; 87.1\%) of the mothers/care takers were aged between $15-34$ years, $44(11.5 \%)$ and $3(0.8 \%)$ were aged $35-54$ years and 55 years and above respectively. Most $(373 ; 97.1 \%)$ of the parents/caretakers were females. Over half $(217 ; 56.5 \%)$ of the parents/caretakers had secondary education, $113(29.4 \%)$ had primary education, $46(12.0 \%)$ had college/university education and only a few $(8 ; 2.8 \%)$ had never been to school. Most (332; 86.5\%) of the mothers/caretakers reported adequate knowledge on malnutrition and $216(56.3 \%)$ reported presence of poverty at home. Majority (302; 78.6\%) of the mothers were HIV negative and 82 (21.4\%) HIV positive. The participants' distribution by residence was as follows; Chawama (140; $36.5 \%)$, Mtendere (124; 32.3\%), Chilenje (67; 17.4\%) and Kabwata (53; 13.8\%) (Table 1).

Table 1: Demographic and socio-economic characteristics of the participants $(\mathrm{N}=384)$

\begin{tabular}{lcc}
\hline Variable & Frequency & Per cent \\
\hline Age of parent & 337 & 87.1 \\
$15-34$ Years & 44 & 11.5 \\
$35-54$ Years & 3 & 0.8 \\
55 Years and above & 11 & \\
Sex of parent/caretaker & 373 & 2.9 \\
Male & & 97.1 \\
Female & & \\
Education Level of parent/caretaker & 8 & 2.1 \\
Never & 113 & 29.4 \\
Primary & 217 & 56.5 \\
Secondary & 46 & 12 \\
College/University & & 52.3 \\
Age of child & 201 & 34.9 \\
$0-11$ Months & 134 & 12.8 \\
$12-24$ Months & 49 & \\
$25-59$ Months & & 51.8 \\
Sex of child & 199 & 48.2 \\
Male & 185 & 16.1 \\
Female & & 71.1 \\
Birth weight of the child & 63 & \\
< 2.5 kg & 273 & \\
$2.5-3.5$ kg & & \\
& & \\
& &
\end{tabular}




\begin{tabular}{lcc}
$>3.5$ kg & 49 & 12.8 \\
Poverty & 216 & 56.3 \\
Present & 168 & 43.8 \\
$\begin{array}{l}\text { Absent } \\
\text { Knowledge }\end{array}$ & 332 & 86.5 \\
Adequate & 52 & 13.5 \\
Inadequate & & \\
Practice & 221 & 57.6 \\
Good & 163 & 42.4 \\
Poor & & \\
Parents'/caretakers HIV status & & 21.4 \\
Positive & 82 & 78.6 \\
Negative & 302 & 17.4 \\
Name of clinic & & 13.8 \\
Chilenje & 67 & 32.3 \\
Kabwata & 53 & 36.5 \\
Mtendere & 124 & \\
Chawama & 140 & \\
\hline
\end{tabular}

\section{Anthropometric measurements}

Majority (296; 77.1\%) of the children had MUAC > $12.5 \mathrm{~cm}, 65(16.9 \%)$ had $11.5-12.5 \mathrm{~cm}$ and 23 (6.0\%) had < $11.5 \mathrm{~cm}$. According to $\mathrm{zH} / \mathrm{A}, \mathrm{zW} / \mathrm{H}$, and zW/A, $263(68.5 \%)$ and $121(31.5 \%), 367$ (95.6\%) and 17 (4.4\%), and $331(86.2 \%)$ and 53 (13.8\%) were normal and stunted, normal and wasted and normal and underweight respectively. The mean (SD) of the age (months), height (cm) and weight (kg) of the children was 13.83 (10.17), 73.25 (10.95) and 9.14 (2.64), respectively (Table 2).

Table 2: Anthropometric measurements $(\mathrm{N}=384)$

\begin{tabular}{lll}
\hline Variable & Frequency & Per cent \\
\hline MUAC & 296 & 77.1 \\
$>12.5 \mathrm{~cm}$ & 65 & 16.9 \\
$11.5-12.5 \mathrm{~cm}$ & 23 & 6 \\
$<11.5 \mathrm{~cm}$ & & \\
Stunting & 263 & 68.5 \\
Normal (zH/A $\geq-2)$ & 121 & 31.5 \\
Stunted (zH/A <-2) & & \\
Wasting & 367 & 95.6 \\
Normal (zW/H $\geq-2)$ & 17 & 4.4 \\
Wasted (zW/H <-2) & & 10.95 \\
Underweight & 331 & 2.64 \\
Normal (zW/A $\geq-2)$ & 53.14 & 86.2 \\
Underweight (zW/A <-2) & 53.8 \\
Age of child (Months; Mean, SD) & & 10.17 \\
Height of child (cm; Mean, SD) & 53 & \\
Weight of child (kg; Mean, SD) & & \\
\hline
\end{tabular}


Key: $\mathrm{N}=$ Number, $\mathrm{kg}=$ kilograms, $\mathrm{cm}=$ Centimetres, $\mathrm{zW} / \mathrm{H}=\mathrm{z}$ score weight for height, $\mathrm{zW} / \mathrm{A}=\mathrm{z}$ score weight for age, $\mathrm{zW} / \mathrm{A}=\mathrm{z}$ score weight for age, $\mathrm{SD}=$ Standard deviation

\section{Determinants of malnutrition}

The Chi-square test used run to select the variables to include into the binary logistic regression model. The distributions of malnutrition by determinants among the participants are shown in Table 3. Stunting, wasting and underweight were associated with child's age and MUAC. In addition, stunting was associated with practices of the parent/caretaker while wasting was associated with child's birth weight and parent's/caretaker's knowledge on malnutrition. However, parent's/caretaker's age, parent's/caretaker's sex, parent's/caretaker's education, child's sex, poverty, parent's/caretaker's HIV status and clinic name were not associated with malnutrition (Table 3).

Table 3: Malnutrition indices by significant determinants $(\mathrm{N}=384)$

\begin{tabular}{|c|c|c|c|}
\hline \multirow{3}{*}{ Characteristic } & \multicolumn{3}{|l|}{ Stunting } \\
\hline & Normal $(\mathrm{N}=263, \mathrm{zW} / \mathrm{H} \geq-2)$ & \multicolumn{2}{|l|}{ Stunted $(N=121, z W / H<-2)$} \\
\hline & $\mathrm{N}(\%)$ & $\mathrm{N}(\%)$ & $P$-value* \\
\hline \multicolumn{4}{|l|}{ Child' age } \\
\hline o-11 Months & $81(40.3)$ & $120(59.7)$ & \\
\hline $12-24$ Months & $133(99 \cdot 3)$ & $1(0.7)$ & 0.001 \\
\hline $25-59$ Months & $49(100 \%)$ & $0(0.0)$ & \\
\hline \multicolumn{4}{|l|}{ Practice } \\
\hline Good & $159(71.9)$ & $62(28.1)$ & \\
\hline Poor & $104(63.8 \%)$ & $59(36.2)$ & 0.050 \\
\hline \multicolumn{4}{|l|}{ MUAC } \\
\hline$>12.5 \mathrm{~cm}$ & $211(71.3)$ & $85(28.7)$ & \\
\hline $11.5-12.5 \mathrm{~cm}$ & $40(61.5)$ & $25838.5)$ & 0.05 \\
\hline \multirow[t]{4}{*}{$<11.5 \mathrm{~cm}$} & $12(52.2)$ & $11(47.8)$ & \\
\hline & Wasting & & \\
\hline & $\begin{array}{l}\text { Normal }(\mathrm{N}=263, \mathrm{zW} / \mathrm{H} \geq- \\
\text { 2) }\end{array}$ & Wasted $(\mathrm{N}=121, \mathrm{zW} / \mathrm{H}<-2)$ & \\
\hline & $\mathbf{N}(\%)$ & $\mathbf{N}(\%)$ & \\
\hline \multicolumn{4}{|l|}{ Child's age } \\
\hline o-11 Months & $186(92.5)$ & $15(7.5)$ & \\
\hline $12-24$ Months & $133(99 \cdot 3)$ & $1(0.7)$ & 0.007 \\
\hline $25-59$ Months & $48(98.0)$ & $1(2.0)$ & \\
\hline \multicolumn{4}{|c|}{ Birth weight of child } \\
\hline$<2.5 \mathrm{~kg}$ & $53(85.5)$ & $9(14.5)$ & \\
\hline $2.5-3.5 \mathrm{~kg}$ & $266(97.4)$ & $7(2.6)$ & 0.001 \\
\hline$>3.5 \mathrm{~kg}$ & $48(98.0)$ & $1(2.1)$ & \\
\hline \multicolumn{4}{|l|}{ MUAC } \\
\hline$>12.5 \mathrm{~cm}$ & $294(99.3)$ & $2(0.7)$ & \\
\hline $11.5-12.5 \mathrm{~cm}$ & $57(87.7)$ & $8(12.3)$ & 0.001 \\
\hline$<11.5 \mathrm{~cm}$ & $16(69.6)$ & $7(30.4)$ & \\
\hline \multicolumn{4}{|l|}{ Knowledge } \\
\hline Adequate & $320(96.4)$ & $12(3.6)$ & \\
\hline \multirow[t]{3}{*}{ Inadequate } & $47(90.4)$ & $5(9.6)$ & 0.05 \\
\hline & Underweight & & \\
\hline & $\begin{array}{l}\text { Normal }(N=263, z W / A \geq- \\
\text { 2) }\end{array}$ & $\begin{array}{l}\text { Underweight }(\mathrm{N}=121, \\
\mathrm{zW} / \mathrm{A}<-2)\end{array}$ & \\
\hline
\end{tabular}




\begin{tabular}{|c|c|c|c|}
\hline \multirow{3}{*}{ Characteristic } & \multicolumn{3}{|l|}{ Stunting } \\
\hline & $\operatorname{Normal}(\mathrm{N}=263, \mathrm{zW} / \mathrm{H} \geq-2)$ & Stunted $(N=121, z W / H<-2)$ & \\
\hline & $\mathrm{N}(\%)$ & $\mathbf{N}(\%)$ & $P$-value* \\
\hline & $\mathbf{N}(\%)$ & $\mathbf{N}(\%)$ & \\
\hline \multicolumn{4}{|l|}{ Child's age } \\
\hline $0-11$ Months & $149(74.1)$ & $52(25.9)$ & \\
\hline $12-24$ Months & $133(99 \cdot 3)$ & $1(0.7)$ & 0.001 \\
\hline $\begin{array}{l}25-59 \text { Months } \\
\text { MUAC }\end{array}$ & $49(100.0)$ & $0(0.0)$ & \\
\hline$>12.5 \mathrm{~cm}$ & $273(92.2)$ & $23(7.8)$ & \\
\hline $11.5-12.5 \mathrm{~cm}$ & $45(69.2)$ & $20(30.8)$ & 0.001 \\
\hline$<11.5 \mathrm{~cm}$ & $13(56.5)$ & $10(43.5)$ & \\
\hline
\end{tabular}

The multivariate binary logistic regression model was tested for multicollinearity, Hosmer and Lemeshow test of model fitness for data, omnibus test of model coefficients and classification accuracy. The dependent variables were stunting, wasting and underweight: Normal (1), stunted, wasted or underweight (2). The results of the multivariate binary logistic regression analysis to predict whether the determinants namely child's age, parents'/caretakers' practices, MUAC, child's birth weight and parents'/caretakers' knowledge on malnutrition were associated with stunting, wasting and underweight revealed that parents'/caretakers' nutritional practices was only statistically significantly associated with stunting while MUAC was statistically significantly associated with stunting, wasting and underweight (Table 4).

Table 4: Multivariate binary logistic regression model of significant determinants related to stunting, wasting and underweight among under-five children

\begin{tabular}{|c|c|c|c|}
\hline & \multicolumn{3}{|l|}{ Malnutrition indices } \\
\hline & Stunting & Wasting & Underweight \\
\hline Determinant variable & AOR (95\% Cl; p-value) & $\begin{array}{l}\text { AOR ( } 95 \% \mathrm{Cl} ; \mathrm{P} \text { - } \\
\text { value) }\end{array}$ & $\begin{array}{l}\text { AOR ( } 95 \% \mathrm{Cl} ; \mathrm{P} \text { - } \\
\text { value) }\end{array}$ \\
\hline \multicolumn{4}{|l|}{ Practices } \\
\hline Good & $0.50(0.27-0.95 ; 0.033)$ & * & * \\
\hline Poor & Ref & & \\
\hline \multicolumn{4}{|l|}{ MUAC } \\
\hline$>12.5 \mathrm{~cm}$ & $0.10(0.01-0.94 ; 0.044)$ & $\begin{array}{l}0.01(0.00-0.10 \\
0.000)\end{array}$ & $\begin{array}{l}0.4(0.01-0.19 \\
0.000)\end{array}$ \\
\hline $11.5-12.5 \mathrm{~cm}$ & 0.18 (0.02-1.95; 0.159) & $\begin{array}{l}0.23(0.04-1.14 \\
0.072)\end{array}$ & $\begin{array}{l}0.26(0.05-1.40 ; \\
0.114)\end{array}$ \\
\hline$<11.5 \mathrm{~cm}$ & Ref & Ref & Ref \\
\hline
\end{tabular}

Significant $p$-value at $p<0.05, A O R=A d j u s t e d$ odds ratio, $\mathrm{Cl}=$ Confidence interval, Ref=Reference category, Practices= mother's child nutritional practices with regard to types of feed, time of introduction of mixed feeding, weaning age, and child food preparation methods, MUAC=Mid-upper-arm-circumference, $\mathrm{cm}=$ centimetres, *Variable not determining wasting and underweight in regression model

The under-five children whose parents'/caretakers' reported good nutritional practices with regard to malnutrition were $50 \%(0.50,95 \% \mathrm{Cl}: 0.27-0.95)$ less likely to be stunted compared to those who reported poor nutritional practices. Also, Under-five children who had MUAC $>12.5 \mathrm{~cm}$ with regard to stunting, wasting and underweight were $90 \%$ (0.10, 95\% Cl: $0.01-0.94), 99 \%(0.01,0.00-0.10)$ and $60 \%(0.4,0.01-0.19)$ less likely to be stunted, wasted and underweight, respectively (Table 4). 


\section{Discussion}

Growth monitoring is an important tool as it helps to detect early and prevent the development of malnutrition and the resultant complications in under-five children (UNICEF, 2012). A package of effective nutritional interventions to reduce the levels of chronic malnutrition includes adequate maternal nutrition during pregnancy and lactation, early initiation of breastfeeding, exclusive breast feeding for the first six months, continued breastfeeding and adequate complementary feeding from 6 to 24 months, and increased micronutrient intakes from beginning of pregnancy to the child's second birth-day (UNICEF, 2012). The effective interventions for treatment of acute malnutrition include the use of specific therapeutic foods, treatment of medical complications for severe cases, and the use of various supplementary foods for moderate cases $(\mathrm{MOH}, 2014)$.

The present study revealed that according to $\mathrm{zH} / \mathrm{A}, \mathrm{zW} / \mathrm{H}$, and $\mathrm{zW} / \mathrm{A}, 31.5 \%, 4.4 \%$, and $13.8 \%$ of the under-five children were stunted, wasted and underweight, respectively. The results are similar to the national rates of $40.0 \%, 6.0 \%$ and $15.0 \%$ of stunting, wasting and underweight among under-five children, respectively (CSO et al., 2014). Based on MUAC, $6.0 \%$ of the under-five children were either severely stunted or wasted. Other studies reported low and high levels of malnutrition with some having a similar pattern to our study while others having a different pattern.

Ramalho et al. (2013) in Brazil reported $\mathrm{zH} / \mathrm{A}$ and $\mathrm{zW} / \mathrm{H}$ of $12.2 \%$ and $6.6 \%$ for under nutrition and overweight among under-five children, respectively. In Pakistan, Iran, and Nigeria the rates of stunting, wasting and underweight among under-five children were $20 \%, 17 \%$ and $21 \% ; 9.53 \%, 8.19 \%$ and 9.66; and 12.5\%, 14.8\% and 8.5\% respectively (Kavosi et al., 2014; Hossam et al., 2010; Akorede \& Abiola, 2013). In addition, $2.6 \%$ of the under-five children had a MUAC less than $12.5 \mathrm{~cm}$ (stunted), $3.4 \%$ had between $12.5-13.5 \mathrm{~cm}$ (wasted) and $94.1 \%$ had MUAC above $13.5 \mathrm{~cm}$ (Normal) (Akorede \& Abiola, 2013). The MUAC results were lower than those obtained in our study.

However, Sahu et al. (2015), Rayhan \& Khan (2006) and Mengistu et al. (2013) reported stunting, wasting and underweight levels of $15.4-74 \%, 10.6-42.3 \%$, and $39-75 \% ; 45 \%, 10.5 \%$ and $48 \%$ and $47.6 \%, 16.7 \%$ and $30.9 \%$ among under-five children in India, Bangladeshi and Ethiopia, respectively. In Kenya, Olack et al. (2011) reported that $47.0 \%$ and $23.4 \%, 2.6 \%$ and $0.6 \%$, and $11.8 \%$ and $3.1 \%$ of under-five children were stunted and severely stunted, wasted and severely wasted, and underweight and severely underweight, respectively. Goma (2013) in Zambia, reported that overall point prevalence for stunting, wasting, and underweight was $32.2 \%, 20 \%$, and $56 \%$, respectively among children two years and below.

The levels of malnutrition in these studies were influenced by a variety of factors. Some of them predicted the levels of malnutrition in this study while others did not. Although parents'/caretakers' education (Akorede \& Abiola, 2013; Goma, 2013; Kavosi et al., 2014), child's age (Olack et al., 2011; Ramalho et al., 2013; Mengistu et al., 2013), child's sex (Kavosi et al., 2014; Olack et al., 2011) and income (Mengistu et al., 2013; Goma, 2013; Akorede \& Abiola, 2013) did not predict malnutrition in this study, they did in other studies.

The variables that predicted malnutrition levels in this study are parents'/caretakers' nutritional practices and MUAC. The current study revealed that under-five children whose mothers reported good nutritional practices were less likely to be stunted compared to those who reported poor nutritional practices. Similarly, poor water supply which is related to poor nutritional practices was associated with stunting, wasting and underweight (Kavosi et al., 2014) while water treatment was only associated with wasting (Mengistu et al., 2013). Poor water supply lead to improper hand-washing and diarrhoea diseases due to loss of nutrients consumed by the child. Thus, planning for public preventive strategies can help to control childhood under-nutrition according to underlying factors of malnutrition in the study population more especially safe water supply (Kavosi et al., 2014).

In addition, hygiene practices (Akorede \& Abiola, 2013; Goma, 2013), food preparation, weaning and food preservation (Goma, 2013) were associated with underweight and feeding practices were associated with stunting and underweight (Mengistu et al., 2013). Inappropriate infant and young child feeding practices, including late initiation of breastfeeding as well as 
inappropriate complementary foods and inappropriate weaning foods are the root causes of malnutrition. During the critical period of early infancy, proper breastfeeding and complementary feeding practices play critical roles (Fuchs et al., 2014). WHO (2012) reported that inappropriate feeding in children is responsible for one-third of the cases of malnutrition. These infants can be saved through the natural protection of mother's milk without any other supplements for up to the first six months of their lives. Thus, many of the nutrition problems we see today would be greatly alleviated with increased exclusive breastfeeding and more education, information and communication on child nutrition to the parents/caretakers (Rohrmann, 2011). This will subsequently improve the poor nutritional status of the children to ensure healthy living for both mothers and their children (Akorede \& Abiola, 2013). There is need to pay special attention on intervention of under-five malnutrition in developing countries such as Zambia.

This study also showed that under-five children who had MUAC $>12.5 \mathrm{~cm}$ were less likely to be stunted, wasted and underweight, respectively. The results are similar to Akorede \& Abiola (2013) in Nigeria were a few of the children (2.6\%) had a MUAC less than $12.5 \mathrm{~cm}$ while $3.4 \%$ had between $12.5-13.5 \mathrm{~cm}$ and $94.1 \%$ had MUAC above $13.5 \mathrm{~cm}$. In Ethiopia, Malawi and Bangladeshi, MUAC and weight gain achieved over the entire treatment episode of severe acute malnutrition (SAM) were strongly correlated (Binns et al., 2015). This presents the possibility for children undergoing outpatient treatment for SAM to be monitored using MUAC as an alternative to weight (Binns et al., 2015). Goossens et al. (2012) reported that, MUAC $\leq 11.8 \mathrm{~cm}$ as therapeutic feeding programs (TFP) admission criterion is a useful alternative to $\mathrm{zW} / \mathrm{H}$ and since MUAC gain parallels weight gain, it may be feasible to use MUAC as both an admission and discharge criterion.

Myatt et al. (2006), also reported that, MUAC is the best in terms of age independence, precision, accuracy, sensitivity and specificity in case-detection method for severe and moderate malnutrition and that it is also simple, cheap and acceptable. MUAC can be used as a proxy for wasting and can be taken by minimally trained health workers making it a quick and reliable method for screening children to identify those who are seriously malnourished (Kaur et al., 2005). Unadjusted MUAC for instance by age may be useful in clinical settings (Hogness, 2005). In comparison of $\mathrm{zW} / \mathrm{H}$ and MUAC in Guatemala, younger children tended to become upset and agitated during both HT and WT measurements and that no such behaviour was observed during the measurement of MUAC (Velzrboer et al., 1983).

There are indications that MUAC could be used adequately as a stand-alone criterion for SAM children to be admitted to and discharged from nutritional rehabilitation programmes. However, studies have shown that the optimum cut off level of MUAC is higher than the conventional cut off points for detection of under-nutrition among children (Kumar et al., 1996; Dairo et al., 2012). The most appropriate MUAC cut-off for discharge is thus unknown. More data are particularly needed on the risks of children with a low $\mathrm{zW} / \mathrm{H}$ not treated for SAM where MUAC is used as a stand-alone criterion. The extent to which factors such as age, sex and stunting affect the rehabilitation outcomes in children admitted with MUAC $<115 \mathrm{~mm}$ must also be clarified (Roberfroid et al., 2013). There is need to develop a MUAC based tool which can be deployed safely and to be used as the anthropometric measure for nutritional assessment either together with the other tools or alone.

Zambia has in the recent past recorded an unprecedented number of malnutrition cases in under-five children. The worsening poverty levels, increased food insecurity as well as the suboptimal infants and young child feeding practices have contributed greatly to malnutrition in Zambia (Simbao, 2009). This consequently has resulted in the alarming rate of morbidity and mortality in children for instance in Lusaka, which situation should be quickly addressed. Malnutrition is a serious concern medically, economically and socially that calls for strong commitment and action. Under-nutrition causes almost 50 per cent of child deaths and reduces a nation's economic growth by at least eight per cent because of direct productivity losses, losses due to poorer cognition, and reduced schooling (Chanda, 2014). Nutritional deficiency makes children vulnerable to contract diarrhoeal diseases, acute respiratory infections and other 
infections that further compound the situation (Hassam et al., 2010). Accordingly, encouraging exclusive breastfeeding for children is essential for their growth, health and development.

Zambia needs to invest more in tackling under-nutrition to sustain current economic growth. The country has introduced the social cash transfer program which is targeted towards the vulnerable where the under nourished children fall (Chanda, 2014). This is besides other malnutrition interventions already in existence. UNICEF supports the delivery of priority interventions at different stages of the life cycle, policy development, system strengthening, service delivery, advocacy, capacity building, partnerships, resource mobilization, innovations, and knowledge management (UNICEF, 2012). Despite strong economic growth, efforts to reduce undernutrition were not getting as much help from general economic growth as they would in many other contexts (Harris et al., 2014) making malnutrition still a serious problem in the country. Motivated by increasing advocacy for nutrition under the Scaling Up Nutrition (SUN) movement, the Zambian government pledged in June 2013 to cut chronic malnutrition by half over the next ten years (Harris et al., 2014). The government has made strong financial pledges in tackling undernutrition, but then again these are far insufficiently reflected in budget allocations (teLintelo, 2014). There is need for Zambia to invest more in nutrition and to address high levels of inequality by targeting those most nutritionally and economically vulnerable (Chanda, 2014).

The limitations of this study are that, there results might have been affected by confounding factors such as parents' age, birth weight of child, clinic site, parents' HIV status, and knowledge about malnutrition among others. The other limitation was probably the two months period of data collection from the participants. In addition, since the study was cross-sectional, it is difficult to establish a "causal" relation between malnutrition prevalence and the factors. Furthermore, only the participants who visited the four clinic sites during the period of data collection were included in the sample. Since the data on under-five clinic cards were incomplete; it was difficult to establish a clear picture of the influence of some variables on malnutrition.

In conclusion, the levels of malnutrition varied depending on the index used and parents' nutritional practices and MUAC predicted these levels. There is still a concern on the child growth monitoring services offered to under-five children at the four clinic sites. Since child malnutrition has serious consequences, more information, education and communication is needed on the part of the parents/caretakers with regard to nutritional practices so that the poor nutritional status of the children can be improved, to ensure healthy living for both parents and their children. This study will enable health care providers to review the child growth and monitoring services offered so as to control under-five malnutrition especially stunting. Further research should be conducted to evaluate the prevalence of over-nutrition among under-five children in the country as it is becoming a problem in the affluent populations.

\section{Ethical considerations}

This study was approved by the University of Zambia Biomedical Research Ethics Committee (Assurance No. FWA00000338, IRBo00011310f IOR G0000774).

\section{Competing interests}

The authors declare that they have no competing interests in the study.

\section{Author's contributions}

EMM, ST, MH, NK, OM, IM and ST conceived and designed the study. ST, MH, NK, OM, IM and ST conducted the study. EMM, ST, MH, NK, OM, IM and ST analysed the data and wrote the manuscript. EMM supervised the whole study process. All the authors read and approved the final manuscript.

\section{Acknowledgements}

We are sincerely grateful to the MoH Zambia and Nursing Education Partnership Initiative (NEPI) for partial sponsorship of this study and the School of Nursing Sciences, University of Zambia for the technical guidance and academic support throughout the research study. We also, thank the 
Clinic In-charges of Chawama, Kabwata, Chilenje and Mtendere Clinics and Lusaka District Medical Office especially the staff in the Clinics for the facilities and support. Finally, our special gratitude goes to the parents/caretakers and the under-five children for their cooperation during the study.

\section{References}

AHETO JM, KEEGAN TJ, TAYLOR BM, AND DIGGLE PJ (2015). Childhood malnutrition and its determinants among under-five children in Ghana. Paediatr Perinat Epidemiol; doi: 10.1111/ppe.12222.

AKOREDE QJ, AND ABIOLA OM (2013). Assessment of nutritional status of under-five children in Akure South Local Government, Ondo State, Nigeria. IJRRAS; 14(3).

BINNS P, DALE N, HOQ M, BANDA C, AND MYATT M (2015). Relationship between mid-upper arm circumference and weight changes in children aged 6-59 months. Archives of Public Health; 73:54. doi:10.1186/s13690-015-0103-y.

CHANDA G (2014). Scott optimistic social cash transfer will tackle under nutrition. The Post newspaper; $24^{\text {th }}$ September, 5 .

CSO [Zambia], MOH [Zambia], and ICF International. Zambia demographic and health survey 2013-14 2014; Rockville, Maryland, USA: CSO, MOH, and ICF International.

DAIRO MD, FATOKUN ME, AND KUTI M (2012). Reliability of the Mid Upper Arm Circumference for the Assessment of Wasting among Children Aged 12-59 Months in Urban Ibadan, Nigeria. Int J Biomed Sci.; 8(2): 140-143. PMCID: PMC3614860.

DINSDALE H, RIDLER C, AND ELLS LT (2011). A Simple guide to classifying BMI in children. Oxford: National obesity observator.

FAO, IFAD and WFP (2014). The State of Food Insecurity in the World 2014. Strengthening the enabling environment for food security and nutrition. Rome, FAO.

FUCHS C, SULTANA T, AHMED T, AND HOSSAIN MI (2014). Factors Associated with Acute Malnutrition among Children Admitted to a Diarrhoea Treatment Facility in Bangladesh. Int J Pediatr.; doi: 10.1155/2014/267806. PMCID: PMC3964844.

GARABED E. ADOLPHE QUETELET (1796-1874) (2007)-The average man and indices of obesity. Nephrology Dialysis Transplantation; 23(1):47-51. http://Doi:10.109/ndt/gfm517.PMID 17870752.

GOMA AC (2013). Determining the point prevalence of malnutrition in children aged two years and below in two urban zonal health centres in Lusaka. UNZA dbase.

GOOSSENS S, BEKELE Y, YUN O, HARCZI G, OUANNES M, AND SHEPHERD S (2012). Mid-Upper Arm Circumference Based Nutrition Programming: Evidence for a New Approach in Regions with High Burden of Acute Malnutrition. PLOS one; DOI: 10.1371/journal.pone.0049320.

HARRIS J, GRÜTZ SS, MASI C, AND HADDAD L (2014). Introduction - Turning Rapid Growth into Meaningful Growth: Sustaining the Commitment to Nutrition in Zambia. September; Institute of Development Studies, Brighton: UK.

HASSAM SL, MAHMOOD-UR-REHMAN, FAHD SL, SALIM W, AND HUMA J(2010). Assessment of nutritional status of 1-5 year old children in an urban union council of Abbottabad. J Ayub Med Coll Abbottabad; $22(3)$.

HOGNESS CG (2005). Severe malnutrition assessment in children in rural Kenya. JAMA; 294(20):2577. 
KAUR G, SING KANG H, SINGAL P, ET AL (2005). Nutritional status:Anthropometric perspective of preschool children. Anthropologist; 7(2):99-103.

KAVOSI E, ROSTAMI ZH, KAVOSI Z, NASIHATKON A, MOGHADAMI M, AND HEIDARI M (2014). Prevalence and determinants of under-nutrition among children under six: a cross-sectional survey in Fars province, Iran. Int J Health Policy Manag; 3(2):71-76. doi.10.15171/ijhpm.2014.63.

KUMAR R, AGGARWAL AK, AND IYENGAR SD (1995). Nutritional status of children: Validity of mid-upper arm circumference for screening under-nutrition. Indian Paediatrics.

MAHGOUB SEO, NNYEPI M, AND BANDEKE T (2006). Factors affecting prevalence of malnutrition among children under three years of age in Botswana, AJFAND; 6(1): ISSN 1684-5378.

MENGISTU K, ALEMU K AND DESTAW B (2013). Prevalence of malnutrition and associated factors among children aged 6-59 months at Hidabu Abote District, North Shewa, Oromia Regional State. J Nutr Disorders Ther; T1, http://dx.doi.org/10.4172/2161-0509.T1-001.

MOH. National Health Strategic Plan (NHSP) 2011-2015: Towards attainment of health related Millennium Development Goals. 2011. Lusaka, Zambia. MOH.

MYATT M, KHARA T, AND COLLINS S (2006). A review of methods to detect cases of severely malnourished children in the community for their admission into community- best therapeutic care programs. Food and Nutr Bull; 27(3 suppl):S7-S23.

OLACK B, BURKE H, LEONARD, COSMAS L, BAMRAH S, DOOLING K, FEIKIN DR, TALLEY LE, AND BREIMAN RF (2011). Nutritional Status of Under-five Children Living in an Informal Urban Settlement in Nairobi, Kenya. J Health Popul Nutr; 29(4):357-363. PMCID: PMC3190366.

PANDVE HT, AND SINGRU SAMIR SA (2012). Various anthropometric methods of assessment of nutritional status in under-five children, Indian Medical Gazette.

RAMALHO AA, MANTOVANI SAS, DELFINO BM, PEREIRA TM, MARTINS AC, OLIART-GUZMÁN H (2013). ET AL. Nutritional status of children under-five years of age in the Brazilian Western Amazon before and after the Interoceanic highway paving: a population-based study, BMC Public Health, 13:1098, doi:10.1186/1471-2458-13-1098.

RAYHAN I, AND KHAN MSH (2006). Factors causing malnutrition among under-five children in Bangladeshi. Pakistan Journal of Nutrition; 5(6):558-562:ISSN 1680-5194.

ROBERFROID D, HAMMAMI N, LACHAT C, PRINZO ZW, SIBSON V, GUESDON B (2013). et al. Utilization of mid-upper arm circumference versus weight-for-height in nutritional rehabilitation programmes: a systematic review of evidence.; Woman and Child Health Research Centre, Institute of Tropical Medicine, 155 Nationalestraat, 2000 Antwerp, Belgium.

ROBERFROID D, PELTO GH, AND KOLSTERN P (2007). Maternal comprehension of growth charts worldwide: Tropical Medicine and International Health; 12(9):1074-1086.

ROHRMANN D (2011). Inappropriate feeding practices root cause of malnutrition, Pakistan. New born NewsHealthy New born Network.

SAHU SK, KUMAR SG, BHAT BV, PREMARAJAN KC, SARKAR S, GAUTAM R, AND NITIN J (2015). Malnutrition among under-five children in India and strategies for control. J Nat Sci Biol Med; 6(1):18-23. doi:10.4103/0976-9668.149072. PMCID: PMC4367032.

SIMBAO K (2009). Malnutrition cases in under-five children on the rise. Lusaka Times. Feb. 18. 
LINTELO DJH (2014). Accountability for International Nutrition Commitment INitiatives, Children's Investiment Fund Founfation and Institute of Development Studies, Institute of Development Studies, Brighton: UK.

UNICEF, WHO and WB. UNICEF-WHO-WB Joint child malnutrition estimates 2015; UNICEF, New York; WHO, Geneva; World Bank, Washington, DC.

UNICEF, WHO, WB, UN. Levels and trends in child mortality; Report 2014 estimates developed by the UN Inter-agency Group for Child Mortality Estimation (UN IGME) 2014; United Nations Children's Fund 3 UN Plaza, New York, New York, 10017 USA.

UNICEF. Improving Child Nutrition. The achievable imperative for global progress 2013; New York: UNICEF.

VELZRBOER MI, SELWYN BJ, SARGENT F (1983). The use of arm circumference in simplified screening for acute malnutrition by minimally trained health workers. J Trop Pediatr; 29(3):159-66.

WHO. Nutrition experts take action on malnutrition 2012; Geneva: WHO.

WHO. WHO Child Growth Standards, Length/height for age, Weight for age, Weight for length, Weight for height, Body mass index, for age, Methods and development 2006; Geneva: WHO.

WHO. WHO child growth standards; Length/height for age, Weight for age, Weight for length, Weight for height, Body mass index, for age, Methods and development 2014; Geneva: WHO.

ZELEKE BM, AND RAHMAN A (2013). Prevalence and determinants of chronic malnutrition among under-five children in Ethiopia, Lifescience Global; 2(3). 